Article

\title{
Similarities and Differences in Mechanical Alloying Processes of V-Si-B and Mo-Si-B Powders
}

\author{
Manja Krüger *, Janett Schmelzer and Maria Helmecke \\ Institute of Materials and Joining Technology, Otto von Guericke University Magdeburg, P.O. Box 4120, \\ Magdeburg 39016, Germany; janett.schmelzer@ovgu.de (J.S.); maria.helmecke@gmx.de (M.H.) \\ * Correspondence: manja.krueger@ovgu.de; Tel.: +49-391-6714516; Fax: +49-391-6714569
}

Academic Editor: Chun-Liang Chen

Received: 31 August 2016; Accepted: 8 October 2016; Published: 14 October 2016

\begin{abstract}
V-Si-B and Mo-Si-B alloys are currently the focus of materials research due to their excellent high temperature capabilities. To optimize the mechanical alloying (MA) process for these materials, we compare microstructures, morphology and particles size as well as hardness evolution during the milling process for the model alloys V-9Si-13B and Mo-9Si-8B. A variation of the rotational speed of the planetary ball mill and the type of grinding materials is therefore investigated. These modifications result in different impact energies during ball-powder-wall collisions, which are quantitatively described in this comparative study. Processing with tungsten carbide vials and balls provides slightly improved impact energies compared to vials and balls made of steel. However, contamination of the mechanically alloyed powders with flaked particles of tungsten carbide is unavoidable. In the case of using steel grinding materials, Fe contaminations are also detectable, which are solved in the $\mathrm{V}$ and Mo solid solution phases, respectively. Typical mechanisms that occur during the MA process such as fracturing and comminution are analyzed using the comminution rate $K_{\mathrm{P}}$. In both alloys, the welding processes are more pronounced compared to the fracturing processes.
\end{abstract}

Keywords: Mo-Si-B; V-Si-B; mechanical alloying; process optimization; impact energy; microstructure; microhardness

\section{Introduction}

In the last few decades, the development of new high temperature materials, e.g., for power plant components, has been oriented towards economic and environmental aspects $[1,2]$. There is considerable interest in increasing the efficiency of thermodynamic processes by the substitution of conventional materials like nickel-based superalloys or heat resistant steels. This might be undertaken using two different approaches with respect to the selection of materials. Firstly, using novel high temperature materials beyond the potential of those materials mentioned above will result in an increase of the thermodynamic efficiency, since the maximum process temperature depends on the maximum temperature capability of the material used for the components. Secondly, by using lightweight materials with similar mechanical properties compared to conventional materials, the reduction of mass inertia will also affect the efficiency of the process. Amongst other refractory metal-based alloys several new molybdenum and vanadium alloys, which follow the approaches described above, provide excellent mechanical properties in a wide temperature range, offering promising possibilities in terms of various high temperature applications [3-9].

Molybdenum has an ultra-high melting point $\left(T_{\mathrm{m}}=2623^{\circ} \mathrm{C}\right)$, high mechanical strength and good ductility. The mechanical properties of molybdenum and molybdenum solid solutions are significantly dependent on the type and the concentration of interstitials, e.g., oxygen, and alloying additions, for example $\mathrm{Zr}, \mathrm{Si}, \mathrm{Nb}$ or various oxides [10-16]. In many research studies molybdenum is alloyed with 6-13 at. \% silicon and 5-12 at. \% boron aimed in the formation of silicides with an outstanding creep 
resistance at ultra-high temperatures of up to $1400^{\circ} \mathrm{C}$ [2,11,16-19]. Coevally, the oxidation resistance of molybdenum alloys is improved by these silicide phases due to the formation of well-sticking protective (boro-)silicate glass layers which form during annealing [20]. It is well-accepted that the most promising microstructures of multi-phase molybdenum alloys (specifically of the Mo-Si-B type) consist of a molybdenum solid solution $\left(\mathrm{Mos}_{\mathrm{ss}}\right)$ matrix phase strengthened by homogeneously distributed silicide particles, which results in balanced mechanical properties at ambient and high temperatures $[2-4,21,22]$.

Vanadium $\left(T_{\mathrm{m}}=1910^{\circ} \mathrm{C}\right)$ offers high strength values, even at high temperatures up to $1430{ }^{\circ} \mathrm{C}$ and simultaneously has a very low density $\left(\varrho=6.11 \mathrm{~g} / \mathrm{cm}^{3}\right)$ in comparison to other high melting point metals or refractory alloys [8]. Vanadium solid solutions $\left(\mathrm{V}_{\mathrm{ss}}\right)$, which are considered as materials for fusion reactors, are alloyed with $\mathrm{Cr}, \mathrm{Si}$ and/or Ti, having typical concentrations in the range between 3 and 6 at. \%, respectively $[6-9,23,24]$. These materials provide high tensile strength values up to $700 \mathrm{MPa}$, but show a drop in strength at temperatures above $700{ }^{\circ} \mathrm{C}$. Oxide or carbide particle reinforced vanadium alloys show improved hardness, long-term stability and creep life at $800{ }^{\circ} \mathrm{C}$ compared to reference alloy V-4Cr-4Ti $[9,25]$. When compared to $\mathrm{V}_{\mathrm{ss}}$ alloys, significantly enhanced mechanical properties are provided by eutectic $\mathrm{V}_{\mathrm{ss}}-\mathrm{V}_{3} \mathrm{Si}$ alloys. These materials have yield strength values of around $600 \mathrm{MPa}$ at $800{ }^{\circ} \mathrm{C}$, showing the substantial potential of silicide reinforced vanadium materials compared to the solid solution V-4Cr-4Ti alloy with only $240 \mathrm{MPa}$ at $800{ }^{\circ} \mathrm{C}$ [26].

Nunes et al. [27] presented a V-Si-B phase diagram that provides similar crystal structures in the V-rich corner as compared to the Mo-rich corner of the Mo-Si-B system [28], namely the $\mathrm{V}_{\mathrm{ss}}$ phase (A2) and the silicides $\mathrm{V}_{3} \mathrm{Si}$ (A15) and $\mathrm{V}_{5} \mathrm{SiB}_{2}$ (T2). This allows us to follow a similar alloying concept as used for the development of Mo-Si-B alloys $[2,21,22]$ for producing silicide reinforced metal matrix materials. While the Mo-Si-B system has been comprehensively researched over the last decade with respect to microstructure evolution, the phase stability as well as the mechanical and oxidation properties [2-4,19-22,28-30] and the properties of alloys from the ternary V-Si-B system are widely unknown. For the model alloy V-9Si-13B, our preliminary results [31] verified the formation of the three phases $\mathrm{V}_{\mathrm{ss}}, \mathrm{V}_{3} \mathrm{Si}$ and $\mathrm{V}_{5} \mathrm{SiB}_{2}$ as expected by the phase diagram [27].

However, the preparation of homogeneous, silicide reinforced vanadium or molybdenum alloys via an ingot-metallurgical process route is difficult since the high melting point or massive differences in the densities of the alloy components result in an economic or procedural limit [21,26,32]. From Mo-Si-B alloys it is well-known that coarse and inhomogeneous microstructures with an intermetallic matrix phase (which typically result from the ingot metallurgical processing) yield in a low fracture toughness and a high brittle-to-ductile transition temperature $[16,21,22]$. A powder metallurgical processing route based on gas atomized powders could be feasible, but the cost-efficiency is low due to high pre-heating temperatures and the expensive process gas, which are required to achieve homogeneous alloy powders [16]. Hence, a powder metallurgical route with a mechanical alloying (MA) process at ambient temperatures provides an energy-efficient alternative which allows us to combine elements with low and high melting points and has significant effects on the subsequent consolidation process since the sintering kinetics is improved by the energy stored in the highly deformed and activated powders [33,34]. Liu and Cui reported on MA of Mo-Si and V-Si powder mixtures and the critical role of the milling conditions for the alloying process and the quality of the final products [35]. They show that milling of V-Si powders using a comparably low energy led to amorphization, while higher energy milling resulted in the formation $\mathrm{V}_{3} \mathrm{Si}$ and $\mathrm{V}_{5} \mathrm{Si}_{3}$ intermetallic compounds. Liu and Cui used vials and milling balls made of steel and tungsten carbide to provide various activation energies during the milling process of the binary alloys.

Our present study focuses on MA processes of model alloys taken from the three-phase regions of the $\mathrm{V}_{\mathrm{ss}}-\mathrm{V}_{3} \mathrm{Si}-\mathrm{V}_{5} \mathrm{SiB}_{2}$ and the $\mathrm{Mo}_{\mathrm{ss}}-\mathrm{Mo}_{3} \mathrm{Si}-\mathrm{Mo}_{5} \mathrm{SiB}_{2}$ system, respectively, aiming for the fabrication of ultrafine and homogeneous V-Si-B and Mo-Si-B (supersaturated) solid solution powders. Such properties are essential for achieving homogeneous compact materials after hot pressing or field-assisted sintering which provide the desired metal-matrix microstructure reinforced with silicide 
phases $[11,16,19]$. A variation of the rotational speed of the planetary ball mill and the type of grinding materials enables the variation of the impact energy and, therefore, helps to optimize this process. The quantity of the energy transfer due to the appearing impact forces between the milling balls, the powder particles and the wall of the vials is decisive for the progress of the MA process and, therefore, the development of homogeneous pre-alloyed powders. High quality MA powders in turn affect the properties of the bulk materials after consolidation, which are well-known for different multi-phase materials [36]. Therefore, in this work a consideration of the kinetic energy transferred into the powders during MA is considered in terms of microstructural changes, the morphology, the size and the hardness of the powders.

\section{Experimental Procedure}

For this study the alloy compositions V-9Si-13B and Mo-9Si-8B (all compositions in at. \%), were chosen from the respective ternary phase diagrams described by Nunes et al. [27] and Sakidja and co-authors [28]. The intention of selecting these compositions was to control an equalized proportion of silicide phases and solid solution phases, in order to enable a balance of high temperature strength and low temperature ductility. For this purpose V (purity: $>99.9 \%$ ), Mo (purity: $99.95 \%$ ), $\mathrm{Si}$ and B powders (purity: $99.9 \%$ ) were prepared under protective argon atmosphere (without any additional control agents) and milled in a planetary ball mill (Retsch ${ }^{\circledR}$ PM 400, Haan, Germany) with a powder-ball ratio of 1:14. To investigate the influence of several process parameters different milling conditions were applied (Table 1). Using a variation of the rotational speed of the planetary ball mill (150 rpm, $200 \mathrm{rpm}$ ) and the utilization of different grinding tools-namely vials and balls made of stainless steel (SS; $d=10 \mathrm{~mm}$ ) and tungsten carbide (WC; $d=8 \mathrm{~mm}$ )—different impact energies due to ball-powder-wall collisions were generated during the milling process (Table 1). Samples for analyses were taken by interrupting the milling process at defined periods of time $(1 \mathrm{~h}, 2 \mathrm{~h}, 5 \mathrm{~h}, 10 \mathrm{~h}, 20 \mathrm{~h}$ and $50 \mathrm{~h}$ ). For all trials, $\mathrm{X}$-ray diffraction (XRD) measurements using a $\mathrm{X}^{\prime}$ Pert powder diffractometer (PANalytical, Kassel, Germany) with $\mathrm{Cu}-\mathrm{K} \alpha$ radiation were performed to analyze the MA progress concerning the presence of elemental $\mathrm{Si}$ or $\mathrm{B}$ to estimate the $\mathrm{V}(\mathrm{Si}, \mathrm{B})$ and $\mathrm{Mo}(\mathrm{Si}, \mathrm{B})$ solid solution formation. Furthermore, particle size measurements were conducted with laser diffraction analysis (Mastersizer ${ }^{\circledR}$ 2000, Malvern, UK) in purified water dispersion and evaluated based on the Fraunhofer diffraction theory. An investigation of the microstructure as well as the particle morphology was carried out by scanning electron microscopy (SEM; ESEM XL30 FEI/Philips, Hillsboro, OR, USA) combined with Energy Dispersive X-ray (EDX) analysis. Prior to that, the powder samples were mounted in a cold embedding material (Technovit 4071, Heraeus Kulzer, Wehrheim, Germany), ground using SiC paper with a grit of 500, 800,1200, and polished with a 3 and $1 \mu \mathrm{m}$ diamond suspension. Iron contamination was quantified using EDX measurements in selected areas of minimum 30 large powder particles or particle agglomerates. Since the quantification of boron cannot be performed by EDX measurements, the amount of boron was assumed to be equal to the nominal composition for the calculation of the Fe concentration. The quantity of tungsten carbide impurities was evaluated on the basis of high contrast SEM micrographs using the Image J software. Moreover, microindentation tests were performed at the embedded powder particles using a Vickers indenter (HV 0.01) and an indentation time of $5 \mathrm{~s}$, including a series of 30 experiments per sample. The optimum set of the parameters for MA (which resulted from this study) was used to produce larger quantities of pre-alloyed powders to investigate the phase evolution during compaction. Therefore, the MA powders of alloys V-9Si-13B and Mo-9Si-8B were compacted using the field assisted sintering (FAST) process. First, the loose, pre-alloyed powders were filled in a graphite die-and-punch unit, and were directly heated by a DC current utilizing the Joule effect. A heating rate of $100 \mathrm{~K} / \mathrm{min}$ up to $1500{ }^{\circ} \mathrm{C}$ or $1600{ }^{\circ} \mathrm{C}$ for the V-9Si-13B and the Mo-9Si-8B alloys, respectively, followed by a 15 min holding time, was used to consolidate the samples. The whole process was performed under vacuum $(P<10 \mathrm{~Pa})$ and a uniaxial pressure of $50 \mathrm{MPa}$. Samples for SEM investigation were prepared from the compact buttons by electrical discharge machining and 
grinding from 180 grit down to 1200 grit, followed by mechanical polishing with a $3 \mu \mathrm{m}$ and $1 \mu \mathrm{m}$ diamond suspension successively and then finished using colloidal silica.

Table 1. Milling conditions, process parameters and energy of collision after Abdellaoui and Gaffet [37], in V-9Si-13B and Mo-9Si-8B powders.

\begin{tabular}{|c|c|c|c|c|c|c|c|}
\hline \multirow{3}{*}{$\begin{array}{c}\text { Alloy Composition (at. \%) } \\
\text { Grinding Material } \\
\text { speed ball mill (rpm) }\end{array}$} & \multicolumn{4}{|c|}{ V-9Si-13B } & \multicolumn{3}{|c|}{ Mo-9Si-8B } \\
\hline & \multicolumn{2}{|c|}{ Steel (SS) } & \multicolumn{2}{|c|}{ Tungsten Carbide (WC) } & \multirow{2}{*}{$\begin{array}{c}\text { Steel } \\
150\end{array}$} & \multicolumn{2}{|c|}{ Tungsten Carbide } \\
\hline & 150 & 200 & 150 & 200 & & 200 & 200 \\
\hline$E_{\text {kin }}$ collision (mJ/hit) & 11.6 & 20.6 & 11.9 & 21.2 & 11.6 & 20.6 & 21.2 \\
\hline milling time to achieve homogenization (h) & 20 & $10-20$ & 20 & 10 & 50 & 20 & 20 \\
\hline Fe impurities in the homogenized particles (at. \%) & $<2$ & $<2$ & & & $<2$ & $<2$ & \\
\hline WC particles in the homogenized particles (\%) & & & 0.2 & 0.45 & & & 0.8 \\
\hline Fe impurities after $50 \mathrm{~h}$ of milling (at. \%) & $<2$ & $<2$ & & & $<2$ & 6.7 & \\
\hline WC particles after $50 \mathrm{~h}$ of milling (\%) & & & 0.75 & 1.75 & & & 1.7 \\
\hline
\end{tabular}

\section{Results and Discussion}

\subsection{Microstructure Evolution}

Table 1 summarizes the technical parameters used for this comparative study on MA of V-Si-B and Mo-Si-B powders. It is expected that the type of grinding tools and the rotational speed of the planetary ball mill will influence the milling behavior. To get an idea about the effect of the specific parameters a constitutional assumption of the kinetic energy $E_{\text {kin, }}$, which is transferred from the grinding balls to the powders during ball-powder collisions, is given by Abdellaoui and Gaffet [37], which is based on the fundamental dynamic principle

$$
E_{\mathrm{kin}}=\frac{1}{2} m_{\mathrm{b}} v_{\mathrm{c}}^{2}
$$

In this equation, $m_{\mathrm{b}}$ is the mass of the balls and $v_{\mathrm{c}}$ the velocity of the collision. The calculation of $v_{\mathrm{C}}$ is based on specific geometrical conditions of the planetary ball mill that involve the following parameters: $r_{\mathrm{m}}$-distance between the center of the vial and the center of the basic disc of the planetary ball mill, $\omega_{\mathrm{e}}$-angular speed of the basic disc, $r^{*}$-effective radius (i.e., the difference between the vial radius and the ball radius), $\omega_{\mathrm{r}}$-angular speed of the vials and $\alpha$-angular position of the ball in the vial:

$$
v_{\mathrm{c}}=\sqrt{r_{\mathrm{m}}^{2} \omega_{\mathrm{e}}^{2}-2 r_{\mathrm{m}} \omega_{\mathrm{e}} r * \omega_{\mathrm{r}} \sin \alpha+r *^{2} \omega_{\mathrm{r}}^{2}}
$$

The calculated values of the collision energy $E_{\text {kin }}$ are summarized in Table 1 for all milling experiments performed in this study. The specific process parameters used for the calculations are given in Table 2. It is obvious that there is a significant difference of the impact energy for milling processes performed at $150 \mathrm{rpm}$ and $200 \mathrm{rpm}$, whereas the type of grinding material seems to have a minor effect.

Table 2. Parameters for the calculation of $v_{\mathrm{c}}$ and $E_{\mathrm{kin}}$.

\begin{tabular}{cccccc}
\hline Grinding Material & Steel & \multicolumn{5}{c}{ Tungsten Carbide } \\
\hline ball mill speed (rpm) & 150 & 200 & 150 & 200 \\
$m_{\mathrm{b}}(\mathrm{kg})$ & 0.004 & & & 0.006 & \\
$\omega_{\mathrm{e}}\left(\mathrm{s}^{-1}\right)$ & 15.71 & 20.93 & 15.71 & & 20.93 \\
$\omega_{\mathrm{r}}\left(\mathrm{s}^{-1}\right)$ & 39.25 & 52.35 & 39.25 & & 52.35 \\
$r_{\mathrm{m}}(\mathrm{m})$ & 0.150 & & & 0.150 & \\
$r^{*}(\mathrm{~m})$ & 0.033 & & & 0.034 & \\
$\alpha$ & 14.87 & 14.91 & 14.94 & & 15.10 \\
\hline
\end{tabular}

Representative X-ray diffractograms of the milling progress of V-9Si-13B powders are presented in Figure 1. While the diffractogram of the untreated V-9Si-13B powder composition ( $0 \mathrm{~h}$; corresponds to the elemental powder mixture) clearly shows the characteristic peaks of the pure elements, the 
formation of a $\mathrm{V}(\mathrm{Si}, \mathrm{B})$ solid solution is significantly progressed after $2 \mathrm{~h}$ of milling as shown in Figure $1 \mathrm{a}$. Only small peaks of Si remain after that short milling time which is in good agreement with the results of our previous experiments on the MA of V-Si, Mo-Si and Mo-Si-B powders with Si concentrations in the range between 9 and 15 at. \% [19,38]. Further indicators for the dissolution of Si in the V lattice are the peak shifting (marked with the red line in Figure 1a) as well as an elimination of the clear separation of the $K_{\alpha}$ and $K_{\beta}$ peak due to the varying parameters of the unit cell by the formation of a $\mathrm{V}(\mathrm{Si}, \mathrm{B})$ solid solution. It must be noted that a small amount of boron is also dissolved in the solid solutions. However, this element has a very small solubility $[39,40]$ and a less pronounced effect on the lattice parameters due to its comparatively small atomic radius. Here it is assumed that Si substitutes the $\mathrm{V}$ or Mo sites, respectively, and $\mathrm{B}$ occupies the interstitial sites as it was also observed in a previous study during MA of Mo-Si, Mo-B and Mo-Si-B powders [19]. In general, all observations in the present study follow this trend, but the development of these characteristics is significantly dependent on the milling parameters.
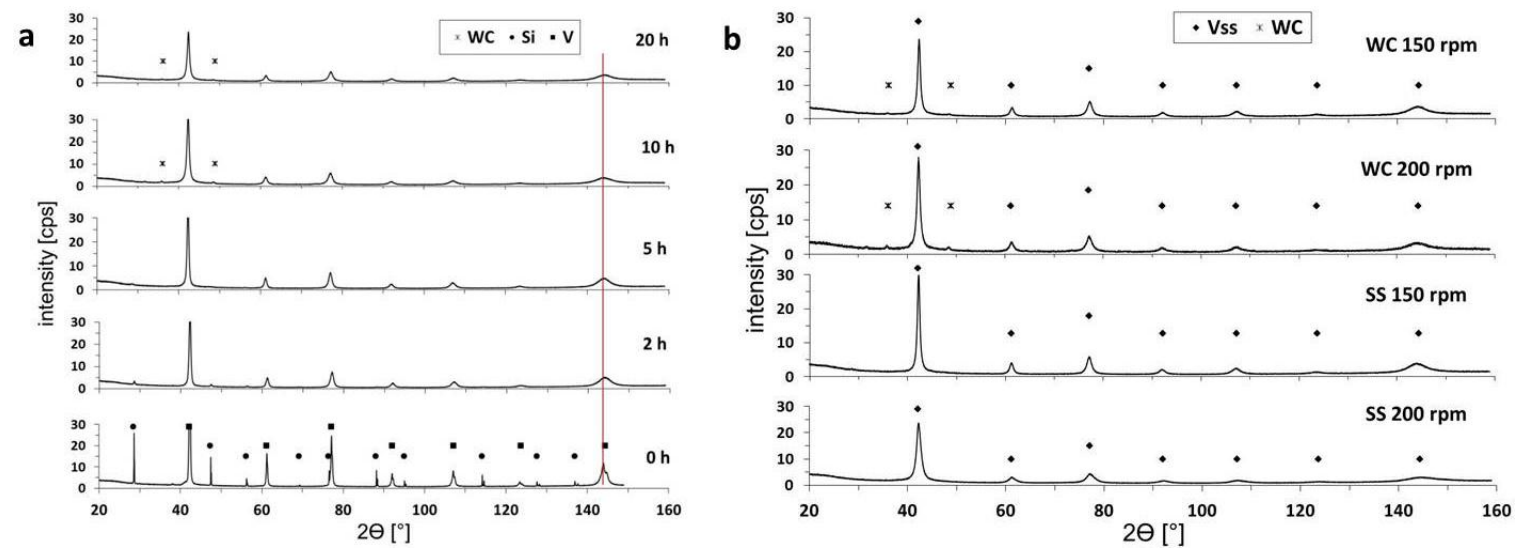

Figure 1. X-ray diffractograms of mechanically alloyed V-9Si-13B powders: (a) milling progress during the treatment with WC tools at $150 \mathrm{rpm}$ and (b) effects of the type of grinding tools (WC-tungsten carbide; SS-stainless steel) and the rotational speed on the milling progress after $20 \mathrm{~h}$.

The data in Table 1 demonstrate that the influence of the rotational speed of the planetary ball mill on the impact energy is more pronounced than the type of grinding materials. The milling progress for both grinding materials correlates proportionally with the increasing impact energy which is strongly influenced by an increased rotational speed of the ball mill. To reach the target of homogeneous pre-alloyed powder particles, the process runs more economically using a rotational speed of $200 \mathrm{rpm}$ due to the reduction of the process time compared to the use of $150 \mathrm{rpm}$. A comparative assessment of the milling progress in V-9Si-13B powders depending on the milling parameters is given in Figure $1 \mathrm{~b}$.

Due to the calculated values for the energy of collision (Table 1) and the meaningful results of the XRD data (Figure 1), it is concluded that MA using a rotational speed of $200 \mathrm{rpm}$ will enable the fastest processing and, therefore, the most efficient way to produce homogeneous particles or even supersaturated solid solution powders. There might be a small additional benefit when using tungsten carbide balls and vials instead of steel materials, but the small difference of the collision energies of $0.6 \mathrm{~mJ} /$ hit is not assumed to contribute significantly to the milling progress at comparatively short milling durations. Though tungsten carbide is a very hard and brittle material, contamination of the mechanically alloyed powders with flaked particles of tungsten carbide (visible by the WC peaks in Figure 1) was already detected after $10 \mathrm{~h}$ of milling (even at comparatively low collision energies at $150 \mathrm{rpm}$ ) yielding in the impurity concentration of $0.2 \%$ after $20 \mathrm{~h}$ of MA. A higher rotational speed of $200 \mathrm{rpm}$ led to an increase of tungsten carbide impurities to an amount of $0.45 \%$ for V-9Si-13B and about $0.8 \%$ for Mo-9Si-8B powders, after $20 \mathrm{~h}$ respectively, which are visible by the bright spots in Figure 2. This fact reduces the attractiveness of this grinding material substantially. The contamination 
with WC particles may be reduced by processing with a lower rotational speed of $150 \mathrm{rpm}$, although this will definitely extend the time needed to achieve homogeneous powder microstructures (Table 1), thus making the process less cost-effective.
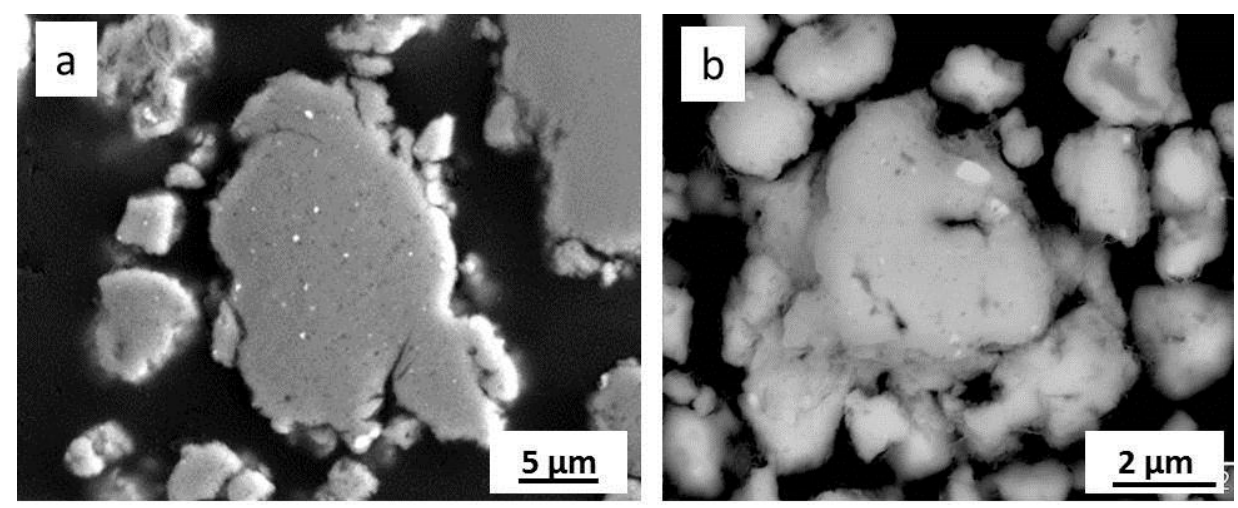

Figure 2. Microstructures of mechanically alloyed powders processed with WC tools after $20 \mathrm{~h}$ at 200 rpm: (a) V-9Si-13B and (b) Mo-9Si-8B. The dark spots are due to remaining Si and B and the white spots are identified as WC particles.

However, there is also contamination in the powders milled in steel vials with steel balls, which grows with increasing impact energy and milling duration (Table 1). Typical values for the Fe contamination detected by EDX analyses are lower than 2 at. \% for all experiments with V-9Si-13B and Mo-9Si-8B powders up to $20 \mathrm{~h}$ of MA. Milling for $50 \mathrm{~h}$ leads to a contamination of the Mo-9Si-8B powders with 6.7 at. \% Fe, while the concentration in V-9Si-13B remains below a level of 2 at. \%. According to the phase diagrams provided by [40], low concentrations of Fe as observed in the MA powders of V-9Si-13B and Mo-9Si-8B are solved in the V or Mo lattice, respectively.

Taking the concentrations and the type of the impurities (WC particles vs. Fe solved in the host lattice) into account, MA leads to higher product quality using stainless steel balls and vials (Table 1). Since oxidation studies by Sossaman and co-authors [41] have shown that minor additions of Fe can improve even the high temperature oxidation performance of Mo-Si-B alloys, Fe contamination seems to be tolerable in this material system. However, the effect of Fe additions in V-Si-B alloys is still unknown.

The microstructure evolution during MA using steel balls and vials is represented in Figure 3 using the example of milling for $2 \mathrm{~h}$ and $20 \mathrm{~h}$ for each trial. Typical mechanisms of multi-component systems during MA are flattening of the ductile components due to high plastic deformation, cold welding and fracturing of the brittle components. These effects influence the microstructure, the particle size and the morphology of the powders. With an increase of the rotational speed from $150 \mathrm{rpm}$ to $200 \mathrm{rpm}$ the impact energy almost doubles from $11.6 \mathrm{~mJ} /$ hit to $20.6 \mathrm{~mJ} /$ hit (Table 1). An effect of the varied energy of collision can be clearly observed by the microstructure evolution after $2 \mathrm{~h}$ of milling (Figure 3). Thus, all micrographs of the powders milled at $200 \mathrm{rpm}$ show the formation of a lamellar microstructure consisting of individual layers of elemental V or Mo (the light grey phases, respectively) and fragmented elemental Si and B (dark grey), which are embedded in the ductile phases. In contrast, larger layers of elemental V or Mo, which is typical in an early state of MA, can still be found after the similar duration of milling using a rotational speed of $150 \mathrm{rpm}$.

After $20 \mathrm{~h}$ of milling the microstructures of the powders make it obvious that a lower energy transfer into the powders will reduce the progress of MA significantly and extend the duration of the process to achieve homogeneous powders and (supersaturated) solid solutions (Figure $3 c, d, g, h$ ). Similar trends as shown for milling with steel tools have been also observed for the process using tungsten carbide vials and balls. In this case, the problem of significant contamination by the abrasive 
wear of the grinding tools accompanied with irregularly dispersed WC particles in the solid solution particles must be taken into account (Table 1 and Figure 2).

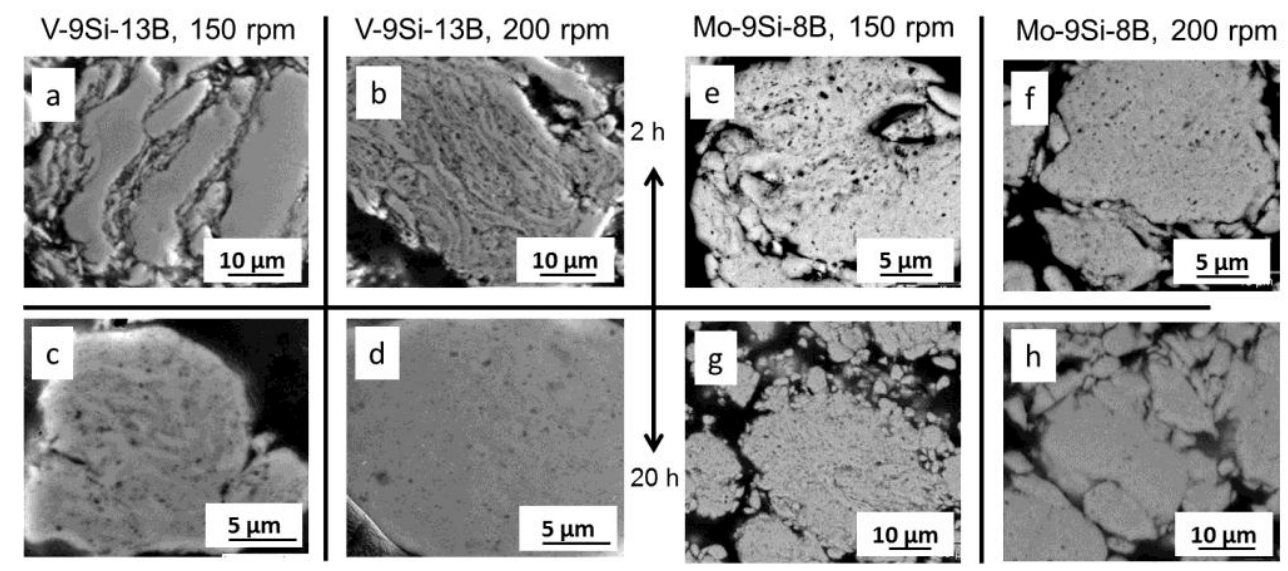

Figure 3. Microstructural evolution of (a-d) V-9Si-13B powders and (e-h) Mo-9Si-8B powders during mechanical alloy (MA) using steel balls and vials.

\subsection{Particle Size and Morphology}

In general, the MA process affects deformation, cold welding and fracturing mechanisms that influence the particle size and the morphology of the powders. Figure 4 shows the particle sizes $\left(d_{50}\right)$ for V-9Si-13B and Mo-9Si-8B powders for different milling trials. The increase of the powder particle size during the initial time of the mechanical alloying process can be explained by a significant deformation of the particles, accompanied with the formation of fresh surfaces and subsequent cold welding processes, specifically of the ductile components $\mathrm{V}$ and Mo in the V-9Si-13B and Mo-9Si-8B powder compositions as also observed in $[34,42,43]$. These effects are also expressed in the micrographs shown in Figure 3.

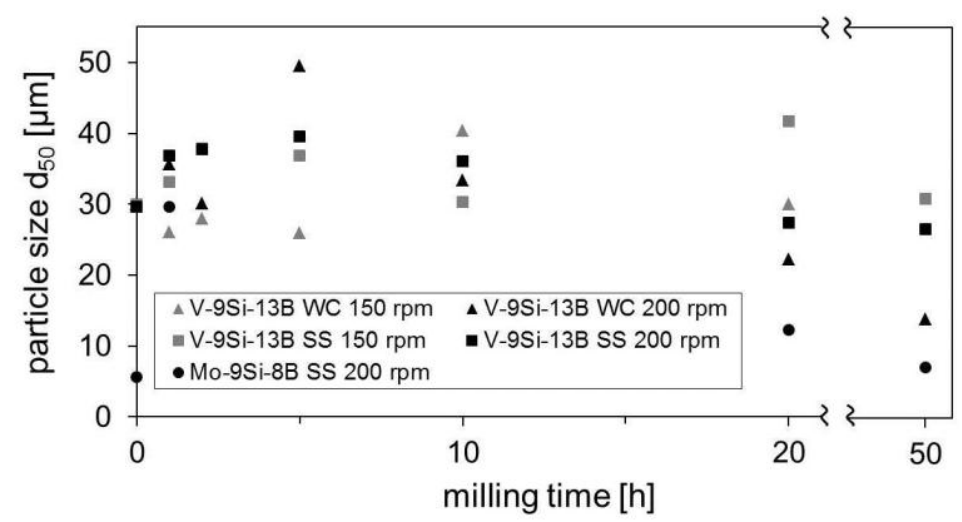

Figure 4. Particle size $\left(d_{50}\right)$ of V-9Si-13B and Mo-9Si-8B powders depending on the milling time.

In the present experiments at $200 \mathrm{rpm}$ the growth of the particles is observed during the first $5 \mathrm{~h}$ of milling which is in good agreement with previous studies on $\mathrm{V}-\mathrm{Si}$ [38] and Mo-Si(-B) [19] powders. A lower kinetic energy, generated by using a rotational speed of $150 \mathrm{rpm}$, extends the duration of welding processes (correlating with rising particle sizes) up to a maximum of $20 \mathrm{~h}$ in the case of V-9Si-13B powders milled with stainless steel tools. Milling durations for periods longer than $50 \mathrm{~h}$ lead to a decrease of the powder particle size.

Figure 5 shows the corresponding morphological evolution of the powders during milling with steel balls and vials at $200 \mathrm{rpm}$ using the example of Mo-9Si-8B. During the initial state of MA the 
particles change their morphological characteristics due to the mechanisms mentioned above; welding processes result in increased particle sizes (in the first $10 \mathrm{~h}$ of the milling process, Figure 4). Thus, during the first hours of MA irregular particle types are formed. Due to the ongoing flattening the particles lose their original morphology, which equalizes during the advanced MA process.
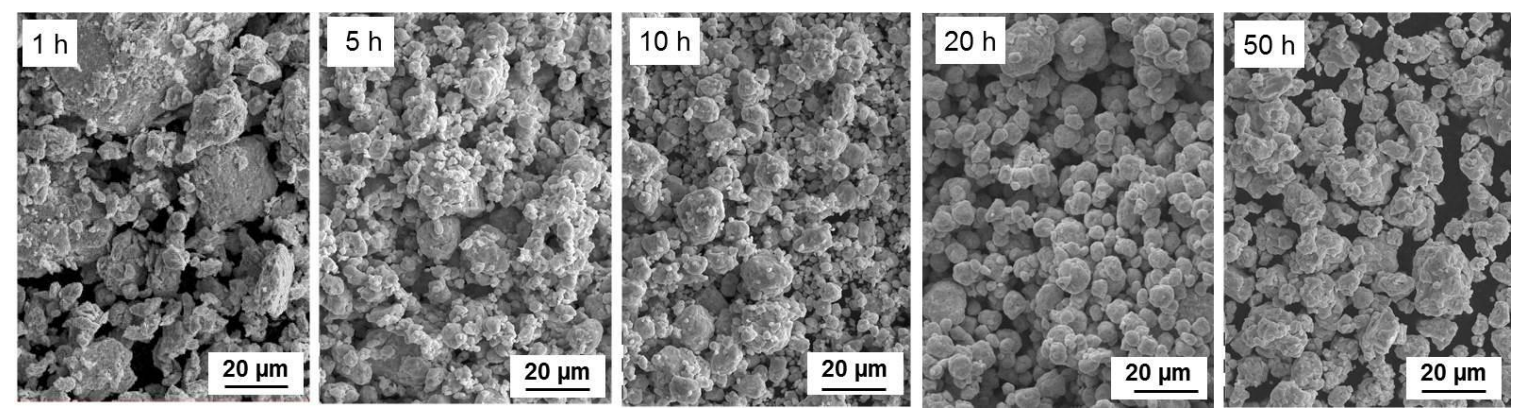

Figure 5. Morphological evolution of Mo-9Si-8B particles depending on the state of MA using steel balls and vials and $200 \mathrm{rpm}$.

After $20 \mathrm{~h}$ of milling the microstructural homogenization is nearly finished as presented in Figure 3 and the particle sizes of both types of alloys are again decreased to the level of the initial powder particle size but have a nearly globular morphology (Figures 4 and 5). This reduction in particle size is due to cold working and strain hardening which increase the brittleness of the particles and support fragmentation or comminution processes until an equilibrium state between welding and fracturing is reached. Similar results have been found in powders of alloy V-9Si-13B milled under the same conditions. It is noticeable that contamination may influence the evolution of the particle size, too. Thus, higher concentrations of Fe in Mo-Si-B powders than observed in the present study seem to influence the increase of particle sizes [19].

Generally, the observations at $150 \mathrm{rpm}$ show just a slight deviation from the trend observed at $200 \mathrm{rpm}$. At the beginning of the process the powder particle size remains nearly constant in the range of a few micrometers up to $5 \mathrm{~h}$ of milling using the milling equipment made of WC. In this trial, a significant increase of the particle size was determined after $5 \mathrm{~h}$ of milling. Another finding of the experiments at $150 \mathrm{rpm}$ was the phenomenon of agglomeration of the powder particles with increasing milling time. Similar mechanisms can be observed for the powder particles milled with steel materials using a rotational speed of $150 \mathrm{rpm}$. However, during the mechanical alloying process the powder mixtures become activated which results not only in agglomeration but also in adhesions at the vial wall and the grinding balls. It must be noticed that the lower rotational speed of the planetary ball mill leads to the formation of very strong adhesions on the vial wall for both grinding materials. By contrast, a higher speed of the ball mill and thus a higher energy impact provides flowable powder particles over the whole process time.

\subsection{Microhardness}

The evolution of the microhardness depending on the milling progress is presented in Figure 6. In all case studies the hardness seems to increase during the first $20 \mathrm{~h}$ of MA and then, the values remain nearly constant up to $50 \mathrm{~h}$. In general, the hardening mechanisms that may occur during the MA process are work hardening, grain refinement (Hall-Petch hardening), dispersion hardening and solid solution hardening as observed also in other powder materials $[36,44]$. The hardening by dispersed particles is not taken into account for the present study on V-9Si-13B and Mo-9Si-8B powders since the formation of silicide particles has been found to occur only after annealing or sintering $[19,31]$ or a duration of minimum $100 \mathrm{~h}$ of MA [38]. 


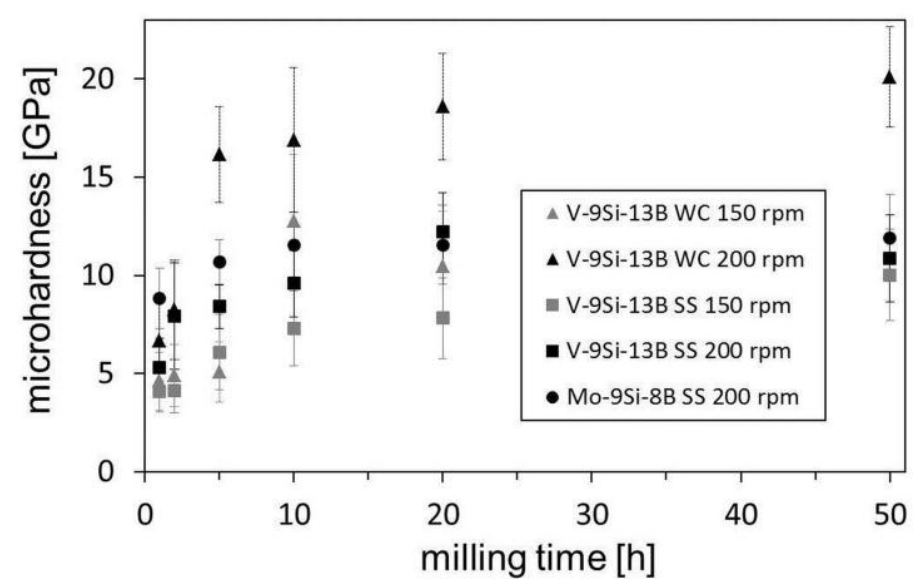

Figure 6. Microhardness evolution of V-9Si-13B and Mo-9Si-8B during the mechanical alloying process using different milling parameters (SS—-stainless steel; WC—tungsten carbide).

However, there are three relevant and coexisting mechanisms working during MA of the V-9Si-13B and Mo-9Si-8B powders which contribute to the evolution of the hardness: Firstly, plastic deformation of the powder particles induced by ball-powder collisions promote work hardening by increasing the dislocation density [45]. This work hardening mechanism has been found to make a major contribution to the total hardness of V-Si alloys [38], which is expected to be analogous in the three-component systems investigated in this study. Secondly, the ball-powder-wall collisions lead to reduced grain or domain sizes down to nanostructures as observed in our preliminary studies on $\mathrm{Mo}-\mathrm{Si}(-\mathrm{B})$ and V-Si powders [19,38] and is also well-known for other materials [44,46]. Thirdly, the microhardness of the powder particles increases due to solid solution strengthening by alloying additions of $\mathrm{Si}$ and B, (and Fe due to the contamination in case of milling with the steel equipment), which are dissolved in the $\mathrm{V}$ and Mo lattice $[19,38,39]$.

All these mechanisms are affected by a variation of the kinetic energy transferred from the grinding balls to the powders (Table 1) and are also dependent on the duration of milling. This is clearly shown in Figure 6, since the data for the powders treated at $150 \mathrm{rpm}$ (grey symbols) show significantly lower hardness in comparison to the powders milled with $200 \mathrm{rpm}$ (black symbols). However, even if the difference in the kinetic energy using steel or WC balls seems to be quite small, i.e., $0.3 \mathrm{~mJ} /$ hit at $150 \mathrm{rpm}$ and $0.6 \mathrm{~mJ} /$ hit at $200 \mathrm{rpm}$, the increased impact energy transferred by the WC balls results in higher hardness values as shown in Figure 6. However, the hardness value might be also influenced by small tungsten carbide particles due to the contamination (Figure 2).

Interestingly, the microhardness values of alloys V-9Si-13B and Mo-9Si-8B develop in a similar manner during processing with the steel equipment using the same milling parameters, yielding in hardness values of around $10 \mathrm{GPa}$ after $20 \mathrm{~h}$ and $50 \mathrm{~h}$ of milling. These values are also in good agreement with the values obtained in earlier milling studies on binary V-Si materials [38]. The consistency of the hardness values beyond milling times of $20 \mathrm{~h}$ is seen to be due to the achieved homogeneous state of the MA powders and the previously observed equilibrium between welding and fracturing (Figures 3-5).

It is noticeable that the microhardness of the supersaturated solid solution powders produced by MA is significantly higher than the values measured in bulk V-Si-B and Mo-Si-B materials in the respective $\mathrm{Moss}_{\mathrm{ss}}$ [22] and $\mathrm{V}_{\mathrm{ss}}$ phases [31], with values of about 9 or $7 \mathrm{GPa}$, respectively. This is due to supersaturation of $\mathrm{Si}$ and $\mathrm{B}$ in the $\mathrm{V}$ or Mo lattice by the MA process compared to the near-equilibrium state after the sintering processes. 


\subsection{Description of the Occurring Process Mechanisms}

Fracturing and comminution as well as welding processes, which are essential for the progress of MA, are highly energy-consuming. Only a minor part of the impact energy is available for significant deformation and fracturing as energy losses (e.g., friction losses, losses for plastic deformation) consume the largest share. The efficiency, which is the relationship between the effective work and the total work spent on the comminution process, is often below $1 \%$. Furthermore, the energy losses lead to a warming of the balls and vials, the powder particles and the milling atmosphere $[47,48]$.

The necessary work for comminution can be approximately determined by half empiric models. Corresponding comminution models described by Rittinger, Kick and Bond combine the specific comminution work $W_{\mathrm{S}}$ with the process result, which is determined by the particle size $d$. The theory of Bond can be used to describe the comminution process for a collective of particles in particular for comminution processes in a planetary ball mill [49-51]. The general comminution law of Bond is given by:

$$
W_{\mathrm{s}, \mathrm{B}}=10 W_{\mathrm{i}}\left(\frac{1}{\sqrt{d_{\mathrm{F}, 80}}}-\frac{1}{d_{\mathrm{I}, 80}}\right)
$$

where $W_{\mathrm{s}, \mathrm{B}}$ : the specific comminution work, $d_{\mathrm{I}, 80}$ : the $80 \%$-particle size of the initial particles, and $d_{\mathrm{F}, 80}$ : the $80 \%$-particle size of the final product. The work index $W_{\mathrm{i}}$ indicates the specific work spent on the comminution process, which is needed to grind the powder particles from an infinite size to a particle size of $d_{\mathrm{F}, 80}=100 \mu \mathrm{m}$ [52]. Since experimental studies have shown that the work index $W_{\mathrm{i}}$ from Equation (3) differed for ultrafine powders milled in a ball mill, Bond [49] suggests a correction factor $A_{\mathrm{i}}$-Equation (4)-if the resulting particle size is expected to be below $70 \mu \mathrm{m}$. This correction factor is necessary to compensate the energy losses that occur during ultrafine size reduction since sticking particles on the milling tools lower the effectiveness of the impact processes:

$$
A_{\mathrm{i}}=\frac{d_{\mathrm{F}, 80}+10.3}{1.145 d_{\mathrm{F}, 80}}
$$

Bond [49] derives this empiric correction factor $A_{\mathrm{i}}$ from a milling process of cement clinker which can be transferred to other materials like quartz [53], talcum [53] and gold ore [54]. By transposing and multiplication of Equations (3) and (4) the modified work index $W_{\text {ic }}$ for ultrafine size reduction according to Bond [49] is as follows:

$$
W_{\mathrm{ic}}=\frac{0.1145 d_{\mathrm{F}, 80} W_{\mathrm{s}, \mathrm{B}}}{\left(d_{\mathrm{F}, 80}+10.3\right)\left(\frac{1}{\sqrt{d_{\mathrm{F}, 80}}}-\frac{1}{\sqrt{d_{\mathrm{I}, 80}}}\right)}
$$

Basically, this modified work index $W_{\mathrm{ic}}$ can be seen as a kind of grinding resistance representing the reciprocal value of the grindability [53]. As a result, the grindability $k$ can be expressed by this equation:

$$
k=\frac{1}{W_{\text {ic }}}
$$

Investigations by Kano et al. [53] for planetary ball milling processes lead to the conclusion that the comminution work $W_{\mathrm{s}, \mathrm{B}}$ can be replaced by the impact energy $E_{\mathrm{Kano}}$ :

$$
E_{\text {Kano }}=\sum_{\mathrm{z}=1}^{n_{\mathrm{s}}} \frac{1}{2 m_{\mathrm{P}}} m_{\mathrm{b}} v_{\mathrm{r}, \mathrm{z}}{ }^{2}
$$

Furthermore, Kano et al. $[53,55]$ present a relationship between the comminution rate $K_{\mathrm{P}}$, the grindability $k$ and the impact energy $E_{\text {kano }}$ as follows:

$$
K_{\mathrm{P}}=k \cdot E_{\mathrm{Kano}}
$$


Assuming that the number of hits is $n_{\mathrm{s}}=1$ and the amount of powder is negligible, the impact energy $E_{\text {Kano }}$ corresponds to the kinetic energy $E_{\text {kin }}$ calculated after Abdellaoui and Gaffet [37] (data presented in Table 1) resulting in:

$$
K_{\mathrm{P}}=k \cdot E_{\text {kin }}
$$

The comminution rate $K_{\mathrm{P}}$ describes the rate constant of the comminution process and gives a representative value for changes of the mechanisms during the milling process [53]. Hence, the comminution rate $K_{\mathrm{P}}$ is used in this work to describe the dominating mechanisms during the MA process as a function of the impact energy.

Based on these relationships, Figure 7 illustrates the behavior of V-9Si-13B and Mo-9Si-8B powders depending on the impact energy $E_{\text {kin }}$ for the respective duration of milling. The comminution rate $K_{\mathrm{P}}$ may have both negative and positive values. Positive values of $K_{\mathrm{P}}$ describe a crushing behavior, in analogy to a size reduction of the particles. The higher the comminution rate, the faster the comminution process of the powder particles. To the contrary, negative values of $K_{\mathrm{P}}$ indicate an increase of the particle size due to cold welding or agglomeration processes occurring during mechanical alloying.

$1 \mathrm{~h}$
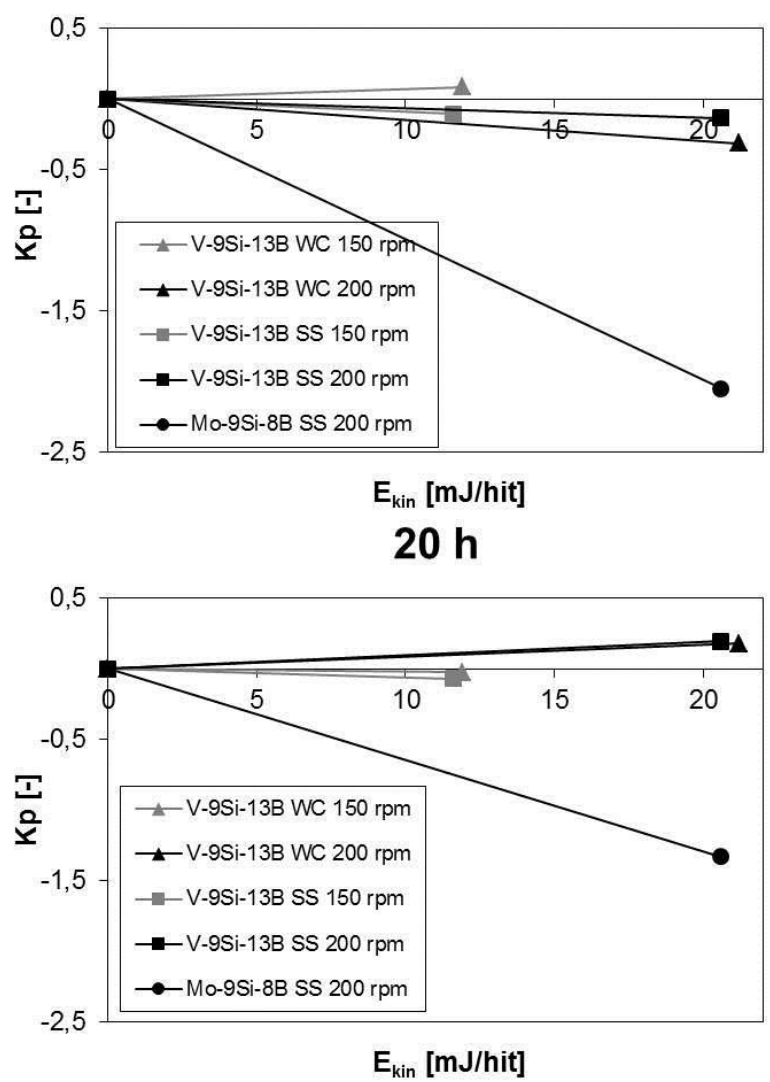

$10 \mathrm{~h}$
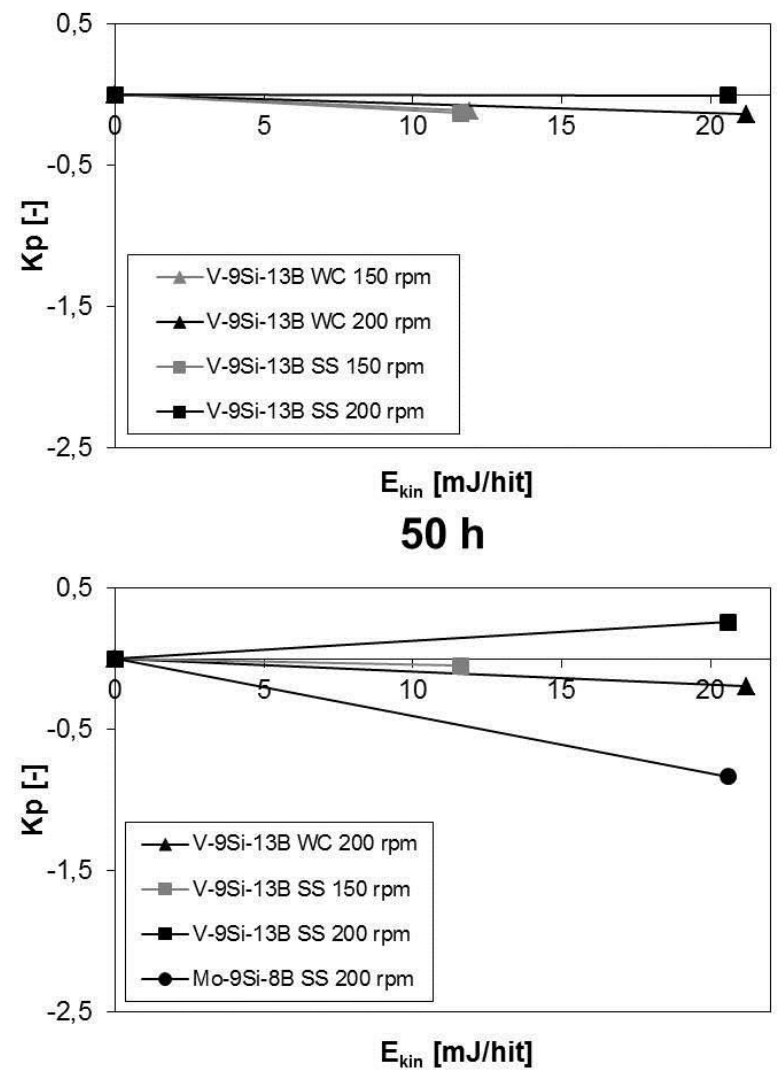

Figure 7. Comparison of the milling behavior of V-9Si-13B and Mo-9Si-8B alloys depending on the duration of milling and the impact energy.

In contrast to Kano et al. [53] who investigated the mechanisms in single-component powders, in the present study on multi-component materials most of the $K_{\mathrm{P}}$ values are not positive (Figure 7). A reason for that is seen in the opposite characteristics of the ductile and brittle alloying elements. The ductile components $\mathrm{V}$ or Mo tend to cold welding (i.e., negative $K_{\mathrm{P}}$ values) and the brittle elements to fracturing $\left(K_{\mathrm{P}}>0\right)$. 
Figure 7 demonstrates the dominance of cold welding processes which is visible by negative $K_{\mathrm{P}}$ values after $1 \mathrm{~h}$ of milling in the experiments performed at $200 \mathrm{rpm}$. The slope of the graphs in Figure 7 is determined as the grindability $k$ (Table 3 ). In the initial process, $k$ did not vary significantly in most of the experiments, which can be seen by the slight slope of the lines. An exception is given in case of the steel processed Mo-9Si-8B alloy. This alloy shows significant particle growth. This effect might be explained by a smaller particle size of the initial Mo-9Si-8B powders in comparison to the $\mathrm{V}-9 \mathrm{Si}-13 \mathrm{~B}$ powders, as the reactive surface of the powders is higher and welding processes are more pronounced. Lower impact energies created by a rotational speed of $150 \mathrm{rpm}$ have relatively low $K_{\mathrm{P}}$ values (between -0.131 and 0.084 ), which indicate that neither the comminution nor the welding process are working significantly.

Table 3. Grindability $k$ and comminution rate $K_{\mathrm{P}}$ of V-9Si-13B and Mo-9Si-8B powders depending on the milling time and the impact energy influenced by the rotational speed of the planetary ball mill and the grinding materials (SS—-stainless steel; WC—-tungsten carbide).

\begin{tabular}{|c|c|c|c|c|c|c|c|c|c|c|}
\hline \multirow{3}{*}{$\begin{array}{l}\text { Duration of } \\
\text { Milling (h) }\end{array}$} & \multicolumn{8}{|c|}{ V-9Si-13B } & \multirow{2}{*}{\multicolumn{2}{|c|}{$\begin{array}{c}\text { Mo-9Si-8B } \\
\text { SS; } 200 \text { rpm }\end{array}$}} \\
\hline & \multicolumn{2}{|c|}{ WC; 150 rpm } & \multicolumn{2}{|c|}{$W C ; 200$ rpm } & \multicolumn{2}{|c|}{ SS; 150 rpm } & \multicolumn{2}{|c|}{ SS; 200 rpm } & & \\
\hline & $k(\mathrm{hit} / \mathrm{mJ})$ & $K_{\mathrm{P}}(-)$ & $k(\mathrm{hit} / \mathrm{mJ})$ & $K_{P}(-)$ & $k(\mathrm{hit} / \mathrm{mJ})$ & $K_{\mathrm{P}}(-)$ & $k(\mathrm{hit} / \mathrm{mJ})$ & $K_{\mathrm{P}}(-)$ & $k(\mathrm{hit} / \mathrm{mJ})$ & $K_{P}(-)$ \\
\hline 1 & 0.007 & 0.084 & -0.015 & -0.312 & -0.009 & -0.107 & -0.007 & -0.136 & -0.099 & -2.047 \\
\hline 10 & -0.010 & -0.115 & -0.007 & -0.138 & -0.011 & -0.131 & -0.001 & -0.006 & - & - \\
\hline 20 & -0.002 & -0.025 & 0.008 & 0.179 & -0.006 & -0.070 & 0.009 & 0.194 & -0.065 & -1.329 \\
\hline 50 & - & - & -0.009 & -0.193 & -0.004 & -0.050 & 0.013 & 0.262 & -0.040 & -0.832 \\
\hline
\end{tabular}

After $10 \mathrm{~h}$ of milling, when the state of homogenization is further advanced, $K_{\mathrm{P}}$ tends to values around 0 , which means that the size reduction and particle growth processes are almost in a state of equilibrium (Table 1). This trend continues up to $20 \mathrm{~h}$ of process time for all V-9Si-13B powders, which had already achieved a homogenized state. Only the Mo-9Si-8B powders continue to weld even after $20 \mathrm{~h}$ of milling with steel balls at $200 \mathrm{rpm}$. This might be due to the effect of the Fe impurities, which are solved in the $\mathrm{Moss}_{\mathrm{ss}}$ phase and may support particle growth [19].

With ongoing process time from $20 \mathrm{~h}$ up to $50 \mathrm{~h}$, the individual process development for each trial proceeds in a similar trend. However, the Mo-9Si-8B alloy still tends to weld. Over process time the slope of the graphs decreased but did not show significant positive values of $K_{\mathrm{P}}$ since the occurring comminution processes did not lead to particle size reductions $\left(d_{\mathrm{F}, 80}\right)$ smaller than the starting particle $\operatorname{size}\left(d_{\mathrm{I}, 80}\right)$.

\subsection{Microstructure of Compact Materials}

Due to the findings described in the previous paragraphs we used milling tools made of steel, a rotational speed of $200 \mathrm{rpm}$ and a milling duration of $20 \mathrm{~h}$ to achieve homogeneous pre-alloyed powder particles in both types of alloys. Such powders were compacted using the field-assisted sintering method as described in Section 2. As expected by the phase diagram, a decomposition of the supersaturated $\mathrm{V}_{\text {ss }}$ powders into the phases $\mathrm{V}_{3} \mathrm{Si}, \mathrm{V}_{5} \mathrm{SiB}_{2}$ and $\mathrm{V}_{\mathrm{ss}}$ is observed during sintering [27]. Since the silicide phases precipitate from the supersaturated $V_{s s}$ phase, they form homogeneously distributed islands, which are embedded in a matrix of the $\mathrm{V}_{\text {ss }}$ phase (Figure 8a). A similar reaction yielding to the phases $\mathrm{Mo}_{\mathrm{ss}}, \mathrm{Mo}_{3} \mathrm{Si}$ and $\mathrm{Mo}_{5} \mathrm{SiB}_{2}$ develops during the compaction of the pre-alloyed Mo-9Si-8B powders (Figure 8b), which is also in good agreement with the respective phase diagram [28].

The type of microstructures we achieved for compact V-Si-B and Mo-Si-B materials appear similar to the microstructure concepts of other multi-phase high temperature materials, like cobalt-based or nickel-based superalloys and $\mathrm{Co} / \mathrm{Ni}$ model superalloys [56-58]. In all cases intermetallic particles are incorporated in a solid solution matrix. 

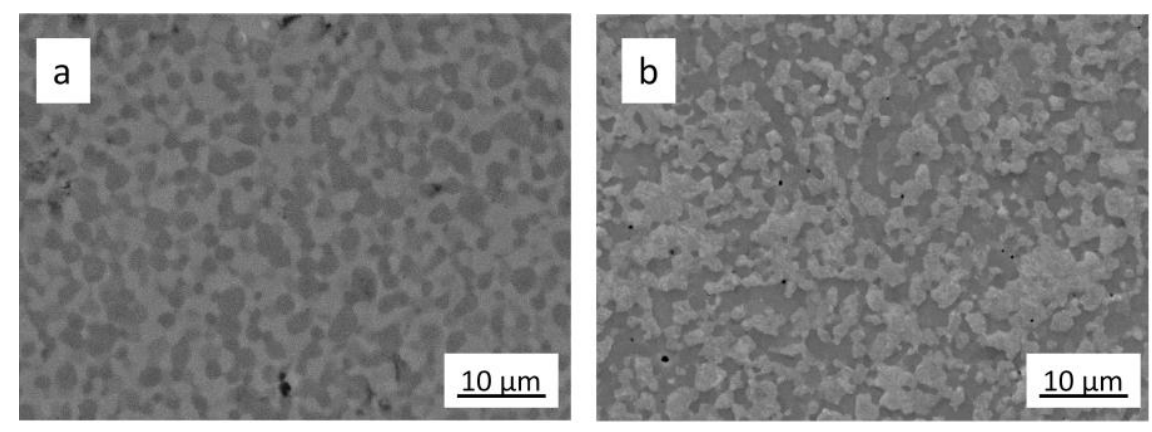

Figure 8. Microstructures of compacts: (a) V-9Si-13B and (b) Mo-9Si-8B.

\section{Summary and Conclusions}

The present study reports on mechanical alloying (MA) processes of V-Si-B and Mo-Si-B model alloys, which are currently the focus of materials research due to their high temperature capabilities. The alloy compositions are taken from the three-phase regions of the $\mathrm{V}_{\mathrm{ss}}-\mathrm{V}_{3} \mathrm{Si}-\mathrm{V}_{5} \mathrm{SiB}_{2}$ and the $\mathrm{Mo}_{\mathrm{ss}}-\mathrm{Mo}_{3} \mathrm{Si}-\mathrm{Mo}_{5} \mathrm{SiB}_{2}$ system, respectively, which is seen as the promising region for the selection of high temperature structural materials. These alloys combine a ductile V or Mo solid solution phase, respectively, with silicide phases providing high temperature strength and oxidation resistance.

The MA process aims for ultrafine and homogeneous (supersaturated) solid solution powders, since such powder characteristics are essential for achieving homogeneous microstructures after hot compaction processes. This provides the desired metal-matrix microstructure reinforced with silicide phases $[11,16,19]$. In order to optimize the MA process, impact energy is adjusted to achieve satisfying powder quality and, at the same time, process parameters are balanced for economic reasons. This is achieved using variation of the rotational speed of the planetary ball mill, the type of grinding materials and the duration of the milling process. Therefore, a consideration of the impact energy transferred during ball-powder-wall collisions during MA is used to discuss the microstructural evolution, the morphology and the hardness of the V-9Si-13B and Mo-9Si-8B powder particles.

The most important conclusions drawn from this comparative study are:

1 MA is shown to be a beneficial process in providing the aimed homogeneous solid solution powders after a duration of 10-20 h of milling depending on the alloy and the process parameters.

2 The progress of MA is significantly dependent on the rotational speed of the planetary ball mill; the material of the grinding balls and vials, i.e., stainless steel and tungsten carbide, are comparably less pronounced.

3 The use of tungsten carbide vials and balls provides just slightly improved impact energies compared to the steel tools. However, tungsten carbide is a very hard and brittle material and contamination of the mechanically alloyed powders with flaked particles of WC is unavoidable, not even when processing with a lower rotational speed. Using grinding materials made of steel, $\mathrm{Fe}$ contaminations are detectable in the milled powders. Due to the solubility of $\mathrm{Fe}$ in the $\mathrm{V}$ and Mo lattice, respectively, these impurities are dissolved in the solid solution phases.

4 The microstructural evolution in both types of alloys follows the same trend: During the first $2 \mathrm{~h}$ of milling, typical layered (lamellar) structures form due to high deformation (flattening) and welding of the ductile elements $\mathrm{V}$ or Mo, respectively, and fracturing of the brittle components. Longer milling or an increased rotational speed of the ball mill leads to the decrease of the lamellar spacing and the homogenization until a supersaturated solid solution phase forms.

5 A balance between economic priorities (short duration of the milling process) and acceptable contamination is made by using milling equipment made of steel; a milling time of $<20 \mathrm{~h}$ in the case of V-9Si-13B and $20 \mathrm{~h}$ in case of Mo-9Si-8B, and a rotational speed of $200 \mathrm{rpm}$. 
6 The evolution of the particle size and the morphology during the initial state of MA is affected by the properties of the individual components, which means that the ductile components flatten and weld during the initial state of MA and the brittle components tend to fracture. These mechanisms yield in irregular powder morphologies. After about $20 \mathrm{~h}$ of milling at $200 \mathrm{rpm}$ nearly globular particles are formed which are seen as appropriate products for subsequent powder consolidation processes.

7 Fracturing and comminution mechanisms which occur during MA can be described by the comminution rate $K_{\mathrm{P}}$. In both types of alloys the welding processes are more pronounced compared to the comminution processes, which is expressed by mainly negative $K_{\mathrm{P}}$ values. During the MA process the slope of the $K_{\mathrm{P}}-E_{\text {kin }}$ graphs decreased but did not show significant positive values of $K_{\mathrm{P}}$ since the occurring comminution processes did not lead to a particle size reduction smaller than the initial particle size of the elemental powders.

8 The compact V-9Si-13B and Mo-9Si-8B materials show the desired microstructures consisting of a $\mathrm{V}_{\mathrm{ss}}$ or $\mathrm{Mo}_{\mathrm{ss}}$ matrix and dispersed particles of the silicide phases.

Acknowledgments: Some of the results presented from V-Si-B powders have been achieved in the framework of the DFG Graduate School 1554 "Micro-macro interactions of structured media and particle systems". We acknowledge our student M. Hellriegel for preparing the micrographs of the V-9Si-13B alloy powders processed with steel tools. The authors are grateful to F. Gang for the compaction of the pre-alloyed powders. We thank the Methodisch-Diagnostisches Zentrum Werkstoffprüfung e.V. Magdeburg for providing the materials for the preparation of the powders. The equipment for the particle size measurements was provided by the Department of Mechanical Process Engineering of the Otto-von-Guericke University Magdeburg, P. Müller, and is greatly acknowledged.

Author Contributions: M. Krüger conceived and designed the experiments and she performed the experiments and analyzed the data of alloy Mo-9Si-8B; J. Schmelzer and M. Helmecke performed the experiments and analyzed the behavior of V-9Si-13B powders; M. Krüger wrote the paper with contributions from J. Schmelzer.

Conflicts of Interest: The authors declare no conflict of interest.

\section{References}

1. Boyce, M.P. Gas Turbine Engineering Handbook 11. In Gas Turbine Engineering Handbook; Elsevier: New York, NY, USA, 2012; pp. 493-514.

2. Soboyejo, W.O.; Srivatsan, T.S. Introduction to Advanced Materials. In Advanced Structured Materials; CRC Press: Boca Raton, FL, USA, 2006.

3. Dimiduk, D.M.; Perepezko, J.H. Mo-Si-B Alloys: Developing a Revolutionary Turbine-Engine Material. MRS Bull. 2003. [CrossRef]

4. Heilmaier, M.; Krüger, M.; Saage, H.; Rösler, J.; Mukherji, D.; Glatzel, U.; Völkl, R.; Hüttner, R.; Eggeler, G.; Somsen, C.; et al. Metallic Materials for Structural Applications Beyond Nickel-based Superalloys. JOM 2009, 61, 61-67. [CrossRef]

5. Yao, Z.; Stiglich, J.; Sudarshan, T.S. Molybdenum Silicide Based Materials and Their Properties. J. Mater. Eng. Perform. 1999, 8, 291-304. [CrossRef]

6. Matsui, H.; Fukumoto, K.; Smith, D.L.; Chung, H.M.; van Witzenburg, W.; Votinov, S.N. Status of vanadium alloys for fusion reactors. J. Nucl. Mater. 1996, 233-237, 92-99. [CrossRef]

7. Smith, D.L.; Chung, H.M.; Loomis, B.A.; Matsui, H.; Votinov, S.; van Witzenburg, W. Fusion Engineering and Design Development of vanadium-base alloys for fusion first-wall-blanket applications. Fusion Eng. Des. 1995, 29, 399-410. [CrossRef]

8. Shyrokov, V.V.; Vasyliv, C.B.; Shyrokov, O.V. Ways of improving the high-temperature work service of vanadium and some alloys used in reactors. J. Nucl. Mater. 2009, 394, 114-122. [CrossRef]

9. Zheng, P.F.; Nagasaka, T.; Muroga, T.; Chen, J.M. Microstructures and mechanical properties of mechanically alloyed V-4Cr-4Ti alloy dispersion strengthened by nano-particles. Fusion Eng. Des. 2014, 89, 1648-1652. [CrossRef]

10. Northcott, L.; Meyer-Zürich, H.U. Molybdenum, von L Northcott. Reihe: Metallurgy of the rarer Metals, Bd. V, herausgeg. von H.M. Finniston. Butterworths Scientific Publications, London 1956. 1. Aufl. Angew. Chem. 1959, 71, 91-91. 
11. Krüger, M.; Schliephake, D.; Jain, P.; Kumar, K.S.; Schumacher, G.; Heilmaier, M. Effects of Zr additions on the microstructure and the mechanical behavior of PM Mo-Si-B alloys. JOM 2013, 65, 301-306. [CrossRef]

12. Saage, H.; Krüger, M.; Sturm, D.; Heilmaier, M.; Schneibel, J.; George, E.; Heatherly, L.; Somsen, C.; Eggeler, G.; Yang, Y. Ductilization of Mo-Si solid solutions manufactured by powder metallurgy. Acta Mater. 2009, 57, 3895-3901. [CrossRef]

13. Sturm, D.; Heilmaier, M.; Schneibel, J.H.; Jéhanno, P.; Skrotzki, B.; Saage, H. The influence of silicon on the strength and fracture toughness of molybdenum. Mater. Sci. Eng. A 2007, 463, 107-114. [CrossRef]

14. Yu, X.J.; Kumar, K.S. The tensile response of Mo, Mo-Re and Mo-Si solid solutions. Int. J. Refract. Met. Hard Mater. 2013, 41, 329-338. [CrossRef]

15. Gunter, I.M.; Schneibel, J.H.; Kruzic, J.J. Ductility and fracture toughness of molybdenum with $\mathrm{MgAl}_{2} \mathrm{O}_{4}$ additions. Mater. Sci. Eng. A 2007, 458, 275-280. [CrossRef]

16. Jéhanno, P.; Heilmaier, M.; Saage, H.; Böning, M.; Kestler, H.; Freudenberger, J.; Drawin, S. Assessment of the high temperature deformation behavior of molybdenum silicide alloys. Mater. Sci. Eng. A 2007, 463, $216-223$. [CrossRef]

17. Hasemann, G.; Bogomol, I.; Schliephake, D.; Loboda, P.I.; Krüger, M. Microstructure and creep properties of a near-eutectic directionally solidified multiphase Mo-Si-B alloy. Intermetallics 2014, 48, 28-33. [CrossRef]

18. Alur, A.P.; Chollacoop, N.; Kumar, K.S. Creep effects on crack growth in a Mo-Si-B alloy. Acta Mater. 2007, 55, 961-974. [CrossRef]

19. Krüger, M.; Franz, S.; Saage, H.; Heilmaier, M.; Schneibel, J.H.; Jéhanno, P.; Böning, M.; Kestler, H. Mechanically alloyed Mo-Si-B alloys with a continuous alpha-Mo matrix and improved mechanical properties. Intermetallics 2008, 16, 933-941. [CrossRef]

20. Rioult, F.A.; Imhoff, S.D.; Sakidja, R.; Perepezko, J.H. Transient oxidation of Mo-Si-B alloys: Effect of the microstructure size scale. Acta Mater. 2009, 57, 4600-4613. [CrossRef]

21. Choe, H.; Chen, D.; Schneibel, J.; Ritchie, R. Ambient to high temperature fracture toughness and fatigue-crack propagation behavior in a Mo-12Si-8.5 B (at. \%) intermetallic. Intermetallics 2001, 9, 319-329. [CrossRef]

22. Krüger, M.; Jain, P.; Kumar, K.S.; Heilmaier, M. Correlation between microstructure and properties of fine grained $\mathrm{Mo}_{-} \mathrm{Mo}_{3} \mathrm{Si}_{-} \mathrm{Mo}_{5} \mathrm{SiB}_{2}$ alloys. Intermetallics 2014, 48, 10-18. [CrossRef]

23. Chaia, N.; David, N.; Mathieu, S.; Vilasi, M. Experimental isothermal section at $1200{ }^{\circ} \mathrm{C}$ of V-Cr-Si system. Intermetallics 2014, 49, 115-120. [CrossRef]

24. Chen, J.M.; Chernov, V.M.; Kurtz, R.J.; Muroga, T. Overview of the vanadium alloy researches for fusion reactors. J. Nucl. Mater. 2011, 417, 289-294. [CrossRef]

25. Sakamoto, T.; Kurishita, H.; Furuno, T.; Nagasaka, T.; Kobayashi, S.; Nakai, K.; Matsuo, S.; Arakawa, H.; Nishimura, A.; Muroga, T. Uniaxial creep behavior of nanostructured, solution and dispersion hardened V-1.4Y-7W-9Mo-0.7TiC with different grain sizes. Mater. Sci. Eng. A 2011, 528, 7843-7850. [CrossRef]

26. Bei, H.; George, E.P.; Kenik, E.A.; Pharr, G.M. Microstructures and mechanical properties of V-V $\mathrm{V}_{3} \mathrm{Si}$ eutectic composites. Z. Metallkunde 2004, 95, 505-512. [CrossRef]

27. Nunes, C.A.; de Lima, B.B.; Coelho, G.C.; Suzuki, P.A. Isothermal Section of the V-Si-B System at $1600{ }^{\circ} \mathrm{C}$ in the V-VSi ${ }_{2}$-VB Region. J. Phase Equilib. Diffus. 2009, 30, 345-350. [CrossRef]

28. Sakidja, R.; Perepezko, J.H.; Kim, S.; Sekido, N. Phase stability and structural defects in high-temperature Mo-Si-B alloys. Acta Mater. 2008, 56, 5223-5244. [CrossRef]

29. Kruzic, J.J.; Schneibel, J.H.; Ritchie, R.O. Fracture and fatigue resistance of Mo-Si-B alloys for ultrahigh-temperature structural applications. Scr. Mater. 2004, 50, 459-464. [CrossRef]

30. Schneibel, J.H. High temperature strength of $\mathrm{Mo}_{-} \mathrm{Mo}_{3} \mathrm{Si}_{-}-\mathrm{Mo}_{5} \mathrm{SiB}_{2}$ molybdenum silicides. Intermetallics 2003, 11, 625-632. [CrossRef]

31. Krüger, M. High temperature compression strength and oxidation of a V-9Si-13B alloy. Scr. Mater. 2016, 121, 75-78. [CrossRef]

32. Reis, D.A.P.; Nunes, C.A.; Neto, A.C. Caracterizacao microestrutural e quimica de ligas V-Si-B. Rev. Bras. Apl. Vácuo 2007, 26, 79-82.

33. Koch, C.C.; Whittenberger, J.D. Mechanical milling/alloying of intermetallics. Intermetallics 1996, 4, 339-355. [CrossRef]

34. Li, B.; Zhang, G.; Jiang, F.; Ren, S.; Liu, G.; Sun, J. Characterization of Mo-Si-B Nanocomposite Powders Produced Using Mechanical Alloying and Powder Heat Treatment. J. Mater. Sci. Technol. 2015. [CrossRef] 
35. Liu, L.; Cui, K. Mechanical alloying of refractory metal-silicon systems. J. Mater. Process. Technol. 2003, 138, 394-398. [CrossRef]

36. Koch, C.C. Intermetallic matrix composites prepared by mechanical alloying-A review. Mater. Sci. Eng. A 1998, 244, 39-48. [CrossRef]

37. Abdellaoui, M.; Gaffet, E. The physics of mechanical alloying in a planetary ball mill: Mathematical treatment. Acta Metall. Mater. 1995, 43, 1087-1098. [CrossRef]

38. Schmelzer, J.; Baumann, T.; Dieck, S.; Krüger, M. Hardening of V-Si alloys during high energy ball milling. Powder Technol. 2016, 294, 493-497. [CrossRef]

39. Massalski, T.B.; Okamoto, H.; Subramanian, P.R.; Kacprzak, L. Binary Alloy Phase Diagrams, 2nd ed.; ASM International: Almere, The Netherlands, 1990.

40. Thermodynamic Properties of Inorganic Materials compiled by SGTE; Springer: Berlin/Heidelberg, Germany; New York, NY, USA, 2007.

41. Sossaman, T.; Sakidja, R.; Perepezko, J.H. Influence of minor Fe addition on the oxidation performance of Mo-Si-B alloys. Scr. Mater. 2012, 67, 891-894. [CrossRef]

42. Yang, T.; Guo, X.; Luo, Y. Microstructural evolution of mechanically alloyed Mo-Si-B-Zr-Y powders. Int. J. Refract. Met. Hard Mater. 2016, 56, 35-43. [CrossRef]

43. Zheng, P.F.; Nagasaka, T.; Muroga, T.; Chen, J.M. Investigation on mechanical alloying process for vanadium alloys. J. Nucl. Mater. 2013, 442, S330-S335. [CrossRef]

44. Koch, C.C. Synthesis of nanostructured materials by mechanical milling: Problems and opportunities. Nanostruct. Mater. 1997, 9, 13-22. [CrossRef]

45. Rösler, J.; Harders, H.; Bäker, M. Mechanisches Verhalten der Werkstoffe, 4th ed.; Springer: Wiesbaden, Germany, 2012.

46. Oda, S.; Kurishita, H.; Tsuruoka, Y.; Kobayashi, S.; Nakai, K.; Matsui, H. High temperature strength of fine-grained, particle-dispersed V-(1.7-2.4)wt. \%Y alloys with different grain sizes and particle densities. J. Nucl. Mater. 2004, 329-333, 462-466. [CrossRef]

47. Höffl, K. Zerkleinerungs- und Klassiermaschinen; Springer: Berlin/Heidelberg, Germany, 1986.

48. Schwister, K.; Leven, V. Verfahrenstechnik für Ingenieure; Carl Hanser Verlag GmbH \& Co KG: Munich, Germany, 2014.

49. Bond, F.C. Crushing and grinding calculations. Br. Chem. Eng. 1961, 6, 378-385.

50. Stieß, M. Mechanische Verfahrenstechnik 2; Springer: Berlin/Heidelberg, Germany, 1997.

51. Jankovic, A.; Dundar, H.; Mehta, R. Relationships between comminution energy and product size for a magnetite ore. J. S. Afr. Inst. Min. Metall. 2010, 110, 141-146.

52. Müller, E.; Oestreich, C. Handling of Highly Dispersed Powders; Shaker Verlag: Aachen, Germany, 2004.

53. Kano, J.; Mio, H.; Saito, F. Correlation of size reduction rate of inorganic materials with impact energy of balls in planetary ball milling. J. Chem. Eng. Jpn. 1999, 32, 445-448. [CrossRef]

54. Gupta, A.; Yan, D.S. Mineral Processing Design and Operation; Elsevier: New York, NY, USA, 2006. [CrossRef]

55. Mio, H.; Kano, J.; Saito, F. Scale-up method of planetary ball mill. Chem. Eng. Sci. 2004, 59, 5909-5916. [CrossRef]

56. Vorontsov, V.A.; Barnard, J.S.; Rahman, K.M.; Yan, H.Y.; Midgley, P.A.; Dye, D. Coarsening behaviour and interfacial structure of g precipitates in Co-Al-W based superalloys. Acta Mater. 2016, 120, 14-23. [CrossRef]

57. Zenk, C.H.; Neumeier, S.; Engl, N.M.; Fries, S.G.; Dolotko, O.; Weiser, M.; Virtanen, S.; Göken, M. Intermediate $\mathrm{Co} / \mathrm{Ni}$-base model superalloys-Thermophysical properties, creep and oxidation. Scr. Mater. 2016, 112, 83-86. [CrossRef]

58. Reed, R.C.; Tao, T.; Warnken, N. Alloys-By-Design: Application to nickel-based single crystal superalloys. Acta Mater. 2009, 57, 5898-5913. [CrossRef]

(C) 2016 by the authors; licensee MDPI, Basel, Switzerland. This article is an open access article distributed under the terms and conditions of the Creative Commons Attribution (CC-BY) license (http:/ / creativecommons.org/licenses/by/4.0/). 